\title{
Molecular cloning, expression and characterization of the zebrafish bram1 gene, a BMP receptor-associated molecule
}

\author{
Kang-mai $\mathrm{Wu}^{1}$, Chang-jen Huang ${ }^{2}$, Sheng-ping L. Hwang ${ }^{3} \& \mathrm{Yu}$-sun Chang ${ }^{4, *}$ \\ ${ }^{1}$ Institute of Microbiology and Immunology, National Yang-Ming University, Shih-Pai 112, Taipei Taiwan; \\ ${ }^{2}$ Institute of Biological Chemistry, Academia Sinica, Nankang, Taipei 11529, Taiwan; ${ }^{3}$ Institute of Cellular \\ and Organismic Biology, Academia Sinica, Nankang, Taipei 11529, Taiwan; ${ }^{4}$ Graduate Institute of Basic \\ Medical Sciences, Chang Gung University, 259 Wen-Hwa 1st Road, Kwei-Shan, Taoyuan 333, Taiwan
}

Received 4 October 2005; accepted in revised form 21 December 2005

(C) 2006 National Science Council, Taipei

Key words: BRAM1, BMPRIA, whole-mount in situ hybridization, real time RT-PCR, zebrafish, BMP signaling

\section{Summary}

We have identified a cDNA clone encoding BMP receptor-associated molecule 1 (BRAM1) from the zebrafish expressed sequence tag (EST) database. The 2606 bp full-length braml cDNA was cloned, and further confirmed by nucleotide sequencing. The zebrafish sequence encodes a protein of 195 amino acids with an evolutionarily conserved MYND domain, which displays $\sim 98 \%$ homology with human and mouse BRAM1, and $\sim 64 \%$ homology with C. elegans BRA-1 and BRA-2. The braml gene, composed of five exons and four introns, spans $\sim 14 \mathrm{~kb}$ on linkage group 14 of the zebrafish genome. RT-PCR and whole mount in situ hybridization analyses disclosed that zebrafish BRAM1 is a maternal factor. The protein interacts directly with zebrafish BMP Receptor type IA, as observed from GST-pull down and co-immunoprecipitation assays. Furthermore, cotransfection of zebrafish BRAM1 with the corresponding BMP receptor resulted in down-regulation of BMP-mediated signaling. Our results collectively indicate that BRAM1 plays a biological role during zebrafish development.

\section{Introduction}

Bone morphogenetic proteins (BMPs) belong to the transforming growth factor (TGF)- $\beta$ superfamily. These proteins contribute to the embryonic development of animals, and are essential for patterning of the embryo along all the body axes $[1,2]$. The BMP signaling pathway, such as the members involving BMP signaling pathway, is highly conserved among different species, including human, mouse and zebrafish (Danio rerio). The pathway is activated through binding of BMP to type I and type II serine-threonine kinase receptors [3], consequently triggering phosphorylation

*To whom correspondence should be addressed. Tel: +886-32118800 ext 5131; Fax: +886-3-2118683, E-mail: ysc@mail. cgu.edu.tw of the type I receptor. This step leads to recruitment of the receptor-regulated Smads (R-Smads), specifically, Smad1, 5 or 8, to the receptor complex [4], and subsequent phosphorylation at the SSXS motif in the C-termini of all R-Smad proteins $[5,6]$. Next, R-Smads are released from type I receptors and assemble with Co-Smad, Smad4, into heteromeric complexes [7-9]. The complexes translocate to the nucleus and participate directly in the modulation of gene expression via specific interactions with other co-activators or co-repressors $[4,10,11]$. In addition to the Smad family, several other proteins are involved in the BMP signaling pathway. These include TGF- $\beta$ activated kinase (TAK1) [12], which also participates in the mitogen-activated protein kinase (MAPK) cascade, and TAK1 binding protein 1 (TAB1) [13]. 
BMP signaling is suppressed by inhibitory Smads or I-Smads. Smad6 and Smad7 inhibit the BMP signaling pathway by competing with RSmad proteins for interactions with the activated type I receptor [14]. Moreover, Smad6 competes with Smad4 to block complex formation [15]. Smad7 forms a complex with the HECT domain ubiquitin ligase, Smurf, and triggers the degradation of receptors or R-Smads via proteasomal and lysosomal pathways [16, 17]. The BMP receptor IA (ALK3) interacts with a cytosolic protein, BRAM1 (BMP receptor-associated molecule 1) [18]. This association is specific, since neither ALK2 nor TGF- $\beta$ type I receptor (T $\beta$ R-I) bind the protein [18]. BRAM1 contains a conserved MYND domain, which mediates protein-protein interactions, including binding to Epstein-Barr virus (EBV)-encoded latent membrane protein 1 (LMP1) [19]. This association leads to inhibition of LMP1-mediated NF- $\kappa$ B activation via targeting of the $\mathrm{I} \kappa \mathrm{B} \alpha$ molecule, suggesting that BRAM1 functions as a negative regulator of LMP1-mediated biological function [19]. To date, two homologs of BRAM1 in C. elegans (BRA-1 and BRA-2) have been identified [20]. Genetic analysis of a BRA-1 null mutant with previously known daf-7 (a TGF- $\beta$ ligand homolog mutant) reveals that BRA-1 is epistatic to $d a f-7$ and $d a f-1$ (a type I receptor homolog) $[21,22]$ and hypostatic to daf14 (a Smad homolog) [23]. Moreover, BRA-1 negatively regulates TGF- $\beta$ signaling by blocking physical interactions between the type I receptor and Smads [21]. However, the physiological role of zebrafish BRAM 1 has yet to be elucidated.

In this study, we isolate zebrafish braml, and report the identification, expression and functional characterization of the corresponding protein that may be involved in early zebrafish development and organogenesis. Further experiments disclose that BRAM1 directly interacts with the BMP receptor, both in vitro and in vivo. A luciferase reporter assay further shows that BRAM1 downregulates BMP signaling in a dose-dependent manner.

\section{Methods}

\section{Fish and embryo maintenance}

Adult zebrafish (Danio rerio) were maintained at $28{ }^{\circ} \mathrm{C}$ under a $14 \mathrm{~h}$ light $/ 10 \mathrm{~h}$ dark cycle. Wild- type zebrafish embryos were obtained from a natural spawning $\mathrm{AB}$ strain, and developmental stages were determined from time after fertilization (hours post-fertilization; hpf) at $28^{\circ} \mathrm{C}$, as well as morphological criteria.

\section{Cloning of zebrafish bram1 cDNA}

A zebrafish cDNA clone (GenBank accession no. $A W 174019$ ) containing part of the braml open reading frame (ORF) was identified by BLAST analysis of the NCBI EST database. Full-length bram 1 cDNA was determined by $5^{\prime}$ RACE studies on a zebrafish cDNA library with the $5^{\prime}$ RACE system Version 2.0 (GibcoBRL). The primers used for the outer and inner $5^{\prime}$-RACE amplification reactions were: GSP1 (5'-TTGGCAGTTGCCT TCATTTAC- $\left.3^{\prime}\right)$ and GSP2 (5'-TGTCTGTGT GCCTTTGTGGATCA-3'). Amplification was performed for a total of 30 cycles under the following condition: $30 \mathrm{~s}$ at $96{ }^{\circ} \mathrm{C}, 30 \mathrm{~s}$ at $65^{\circ} \mathrm{C}$, and $2 \mathrm{~min}$ at $72{ }^{\circ} \mathrm{C}$. The amplified product was cloned into the pUC18 vector (BAYOU BIOLABS). Multiple alignments were performed with CLUSTALW version 1.8 .

\section{GST pull-down assay}

GST-BMPRIA C-terminal protein (from a.a. 201 to the C-terminal end cloned into pGEX-3X expression vector) was produced in E.coli BL21. Briefly, the protein was induced by adding $1 \mathrm{mM}$ isopropyl- $\beta$-D-thiogalactopyranoside (IPTG) for $5 \mathrm{~h}$ at $16{ }^{\circ} \mathrm{C}$. GST fusion proteins were prepared as described by the manufacturer (Pharmacia), and purified with glutathione-agarose beads (Pharmacia). The purity and quantity of recombinant proteins were determined by SDS-PAGE, followed by staining with Coomassie blue.

In vitro transcribed and translated $\left[{ }^{35} \mathrm{~S}\right] \mathrm{Met}-$ labeled BRAM1 was generated using pCDNA3. 1 -BRAM1 in a $50 \mu \mathrm{l}$ reaction containing $\left[{ }^{35} \mathrm{~S}\right] \mathrm{Met}$ (Pharmacia) with the TNT coupled transcriptiontranslation system, according to the manufacturer's instructions (Promega).

The GST pull-down experiment was performed using $10 \mu \mathrm{g}$ GST or GST fusion protein bound to glutathione beads, and $10 \mu \mathrm{l}{ }^{35} \mathrm{~S}$-labeled protein synthesized in vitro in a total volume of $500 \mu \mathrm{l}$ binding buffer $(140 \mathrm{mM} \mathrm{NaCl}, 2.7 \mathrm{mM} \mathrm{KCl}$, $10 \mathrm{mM} \mathrm{Na} \mathrm{HPO}_{4}, 1.8 \mathrm{mM} \mathrm{KH_{2 }} \mathrm{PO}_{4}, \mathrm{pH} \mathrm{7.3)}$ at 
$4{ }^{\circ} \mathrm{C}$ overnight. Beads were extensively washed with binding buffer, resuspended in SDS sample buffer, and separated by SDS-PAGE. Radiolabeled proteins were visualized by autoradiography.

\section{Coimmunoprecipitation}

COS-7 cells were transfected with pCDNA3. 1-BMPRIA-HA and/or pFlag-BRAM1. Cell extracts prepared using RIPA buffer $(50 \mathrm{mM}$ Tris, $\mathrm{pH} 7.5,150 \mathrm{mM} \mathrm{NaCl}, 5 \mathrm{mM}$ EDTA, pH 8.0, and $0.5 \%$ NP-40) supplemented with a complete protease inhibitor cocktail (Roche) were incubated with mouse anti-FLAG M2 affinity gel (Sigma) at $4{ }^{\circ} \mathrm{C}$ overnight with rotation. Next, beads were washed three times with RIPA buffer, and boiled in SDS sample buffer for $5 \mathrm{~min}$. Immunoprecipitated proteins were separated by SDS-PAGE, and electroblotted onto PVDF membranes that were subsequently incubated with mouse anti-FLAG monoclonal antibody M2 (Sigma) or rabbit antiHA polyclonal antibody (Santa Cruz) with 1:1000 or 1:500 dilution, respectively, for $1 \mathrm{~h}$ in $3 \%$ skimmed milk. Tagged proteins were detected using HRP-conjugated secondary antibodies and chemiluminescence (ECL, Pierce).

\section{Luciferase reporter assay}

3T3 cells $\left(5 \times 10^{6}\right)$ were transfected with $1 \mu \mathrm{g}$ $\mathrm{p}(\mathrm{SBE})_{4}$-luc, $1 \mu \mathrm{g}$ BMPRIA-HA and different doses of Flag-BRAM1 by electroporation $(0.24 \mathrm{kv}, 960 \mu \mathrm{F})$. Following transfection, cells were treated with BMP2 $(80 \mathrm{ng} / \mathrm{ml})$ for $16 \mathrm{~h}$ in DMEM containing $0.1 \%$ FBS. A pSV40- $\beta$-galactosidase vector $(50 \mathrm{ng})$ was co-transfected for the monitoring of transfection efficiency. For harvesting, lysis buffer $(200 \mu \mathrm{l})$ was added to each dish and $50 \mu \mathrm{g}$ of the protein-containing supernatant was used for luciferase determination with a luminometer. Additionally, $50 \mu \mathrm{g}$ proteins were assayed for $\beta$-galactosidase activity. Reporter activity is expressed as a ratio of relative light units/ $\beta$-galactosidase activity. Data are presented as mean$\mathrm{s} \pm$ SEM of experiments performed in triplicate.

\section{RT-PCR and Real-time RT-PCR}

Stage-specific total RNA from at least 100 normal embryos was isolated using the Trizol A reagent (Gibco/BRL). Total RNA $(1 \mu \mathrm{g})$ was employed for reverse transcription. The following primers were used: braml, 3'-TGCCACGACAAATACTC CA AGATCTTCAG-5' (sense) and 3'-GTTTGCACT TTCTCTCCATCTCGGCCT-5' (antisense); bmprla, 3'-ATCTACGGCACGCAGGG AAA A5' (sense) and $3^{\prime}$-AGCGCCTGGTTCC CATACGTG-5' (antisense); $b m p 4$, 3'-AGCAGCA TCCCAGAGG ACGAA-5' (sense) and 3'-GTCC TTCCCGTG GCGCCTT-5' (antisense); and ef- $1 \alpha, 3^{\prime}$-GAGGG GCTTGTCGGTGGGA-5' (sense) and $3^{\prime}$-GTG TTGCCTTCGTCCCAATTTCAG- $5^{\prime}$ (antisense). RT-PCR was performed under the following conditions: $45 \mathrm{~s}$ at $96{ }^{\circ} \mathrm{C}, 30 \mathrm{~s}$ at $60^{\circ} \mathrm{C}$, and $30 \mathrm{~s}$ at $72{ }^{\circ} \mathrm{C}$ for 30 cycles. Quantitative RT-PCR was performed in accordance with the manufacturer's instructions, using a LightCycler (Roche Diagnostics) and the FastStart DNA Master SYBR Green I system (Roche Diagnostics) in which fluorescence binds to double-stranded DNA. PCR products were separated on a $2 \%$ agarose gel, and results normalized against data from control mRNA, ef- $1 \alpha$.

\section{Whole-mount in situ hybridization}

Embryos were fixed in 4\% paraformaldehyde. In situ hybridization was performed using a digoxigenin-labeled antisense RNA probe [24]. NBT/ BCIP was employed as a substrate for alkaline phosphatase. To prepare the antisense riboprobe, the EcoRI-XbaI fragment of braml cDNA was subcloned into pBluescriptKS + (Stratagene), linearized by EcoRI digestion, and transcribed with T7 RNA polymerase.

\section{Results and discussion}

Isolation of the zebrafish braml cDNA sequence

BRAM1 is conserved in human, mouse, and C. elegans $[6,7,9]$. To ascertain the presence of BRAM1 in zebrafish, we employed the mouse sequence to search the NCBI EST database, using the tBLAST program. As a result, an EST clone (Accession No. AW174019) containing an insert of $\sim 2.5 \mathrm{~kb}$ displaying a partial open reading frame, translation stop codon, and $3^{\prime}$ untranslated region containing the polyadenylation signal sequence (AATAAA) was identified. Based on the EST sequence, we designed a pair of primers for 
5'RACE analysis. The full-length cDNA obtained was subjected to DNA sequence analysis, Consequently, we identified an additional 387 nucleotides. The nucleotide and deduced amino acid sequences of this gene are shown in Figure 1. Analysis of the $2606 \mathrm{bp}$ cDNA sequence revealed that zebrafish braml contains a 289 bp 5'uncoding region, a 1729 bp 3'uncoding region, poly A-tail, and an ORF from nucleotides 290-877 that encodes a putative protein of 195 amino acids with a 44 residue MYND domain from amino acid 152 to the C-terminus (Figure 1a). The two crucial positions for translational initiation are the purine at -3 and guanine at +4 . Both these nucleotides are conserved in zebrafish cDNA. Additionally, the braml gene is mapped to linkage group 14, based on the Sanger zebrafish genomic sequence project database (http://www.sanger.ac.uk/Projects/D_rerio/blast-server.shtml). The zebrafish braml genomic sequence spans 14,394 bp, encompassing five exons and four introns (Figure 1b). The translation initial codon, ATG, is located on the third exon.

\section{Analysis of zebrafish BRAM1 homologs}

The deduced amino acid sequences of BRAM1 homologs of human, mouse, C. elegans, and Drosophila from the EST library of NCBI are shown in Figure 2a. BRAM1 of human, mouse and zebrafish are highly homologous within the entire sequence, and almost identical within the C-terminal MYND domain (amino acids 151-195) (Figure 2a). The amino acid sequence of zBRAM1 (zebrafish BRAM1), displays 77\%, 75\%, 31\%, and 24-25\% identity to human (hBRAM1), mouse (mBRAM1), C. elegans (BRA-1 \& BRA-2), and Drosophila (CG8569 \& CG1815), respectively, as determined from the CLUSTAL W multiple sequence alignment program (Figure 2a). All homologs contain the highly conserved MYND domain. Specifically, the zebrafish MYND domain displays $98 \%$ identity to hBRAM1 and mBRAM1, $64 \%$ with $C$. elegans, and $40 \%$ and $55 \%$ homology with the Drosophila homologs, CG8569 and CG1815, respectively (Figure 2b). Moreover, zebrafish BRAM1 displays significant homology $(>60 \%)$ with hBRAM1 and mBRAM1 outside the MYND domain, and a lower degree of similarity with C. elegans and Drosophila homologs, suggesting that these proteins play similar biological roles.

\section{Expression of the zebrafish braml gene}

The temporal expression profile of the bramlgene was examined by RT-PCR analysis of mRNA in embryos at different development stages $(0,4,8,10$, 12, 16, 24, 72, $144 \mathrm{hpf}$, and adult fish). The braml transcript was readily detected in embryos upon fertilization (day 0), and levels declined significantly after 4 hpf (Figure 3a). However, expression was slightly enhanced at $72 \mathrm{hpf}$. Interestingly, bram 1 mRNA is present during the early stages of development before the onset of zygotic transcription, indicating that these transcripts are maternally supplied. BRAM1 molecules from human and mouse interact with BMPR-IA, and are therefore possibly involved in BMP-mediated signaling. Accordingly, we hypothesize that these three molecules are expressed in a cooperative manner. To test this hypothesis, we examined the expression profiles of zebrafish bmp receptor type $1 a$ (bmprla) and bmp4. The bmprla message is maternally provided, similar to bram 1, but expression was elevated during the gastrulation stages, followed by a decline until the somitogenesis stages (16 hpf). Expression of bmp4 was absent prior to gastrulation, but showed a regular increase during the gastrulation stages, and decreased during somitogenesis. However, zebrafish braml, bmprla, and bmp 4 mRNA levels were elevated again at the end of somitogenesis, with a peak between 24 and $72 \mathrm{hpf}$, followed by a decrease until the adult stage. Zebrafish ef- $1 a$ appears to be present at a constant level during all the developmental stages examined. To further confirm the RT-PCR data, we performed real-time RT-PCR to compare the amounts of the three transcripts described above during the developmental stages $(0,4,8,10,16,24,30,36,48$, 72 and $144 \mathrm{hpf}$ ). Assuming the level at $24 \mathrm{hpf}$ was 1, we observed that expression of braml was significant before gastrulation and declined during the gastrulation and somitogenesis stages (Figure 3b). Northern blot analysis of adult zebrafish tissues revealed high levels of the braml transcript in the ovary (data not shown). The bmprla level generally increased during cleavage and blastula stages, with a peak at $8 \mathrm{hpf}$. Expression of bmp4 was initiated at $8 \mathrm{hpf}$, and generally decreased until the pharyngula period. Levels of braml, bmprla, and bmp 4 started to increase after $24 \mathrm{hpf}$, and displayed minor peaks at 36 and $48 \mathrm{hpf}$. Our results suggest that zebrafish braml, bmprla, and 
(a) GAG GAA CCT GAG CCC GAG ATG GAA GCA GTC AGT TCT AGT CAA GAG ATT CCA ACA

GCT GTT CCA CAT CAG CCG GAG CGT ATG TCC GTC TCC ACG CAG ACC AAA AAG TCT $\begin{array}{llllllllllllllllll}A & V & P & H & Q & P & E & R & \text { II } & S & V & S & T & Q & T & K & K & S\end{array}$

AGC TCC CCT TCA TCC TCT TCC TCT CCG GCC CCT CGC ATG ATC CAC AAA GGC ACA $\begin{array}{llllllllllllllllll}S & S & P & S & S & S & S & S & P & A & P & R & M & I & H & K & G & T\end{array}$

CAG ACA GTA AAT GAA GGC AAC TGC CAA AAC ATG TGC CAC GAC AAA TAC TCC AAG $\begin{array}{lllllllllllllllllll}Q & \mathrm{~T} & \mathrm{~V} & \mathrm{~N} & \mathrm{E} & \mathrm{G} & \mathrm{N} & \mathrm{C} & \mathrm{Q} & \mathrm{N} & \mathrm{M} & \mathrm{C} & \mathrm{H} & \mathrm{D} & \mathrm{K} & \mathrm{Y} & \mathrm{S} & \mathrm{K}\end{array}$

ATC TTC AGC GAC GTT AAA GAA ATG ATG AAG GCG GAG AAC AAA CGG GAG ACC GAA

$\begin{array}{llllllllllllllllll}\mathrm{I} & \mathrm{F} & \mathrm{S} & \mathrm{D} & \mathrm{V} & \mathrm{K} & \mathrm{E} & \mathrm{M} & \mathrm{M} & \mathrm{K} & \mathrm{A} & \mathrm{E} & \mathrm{N} & \mathrm{K} & \mathrm{R} & \mathrm{E} & \mathrm{T} & \mathrm{E}\end{array}$

CGA GTC CTG AAA GAG GCT CTG GAC AAG CTG CGA GGA GAG ATG GAG GAA GAG AAA

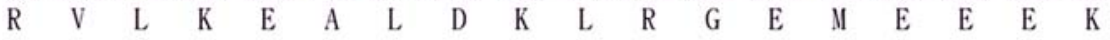

AGG CAG GCG GTG AAC AAA GCG GTG TCC AGC ACG CAG GCC GAG ATG GAG AGA AAG

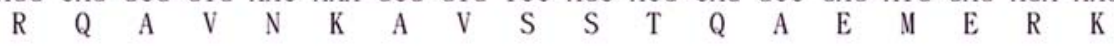

TGC AAA CAG GTG AAG GAG AAG TGC AAA GAG GAG CTC ATG GAG GAG ATG AAG AAG $\begin{array}{llllllllllllllllll}C & \mathrm{~K} & \mathrm{Q} & \mathrm{V} & \mathrm{K} & \mathrm{E} & \mathrm{K} & \mathrm{C} & \mathrm{K} & \mathrm{E} & \mathrm{E} & \mathrm{L} & \mathrm{I} & \mathrm{E} & \mathrm{E} & \mathrm{M} & \mathrm{K} & \mathrm{K}\end{array}$

ATG GTG TCT CAG CAT AAA CAA CTT CTT TCA CAG ACC AAG AAG AAG CAG TGG TGT \begin{tabular}{lllllllllllllllllllll} 
II & $\mathrm{V}$ & $\mathrm{S}$ & $\mathrm{Q}$ & $\mathrm{H}$ & $\mathrm{K}$ & $\mathrm{Q}$ & $\mathrm{L}$ & $\mathrm{L}$ & $\mathrm{S}$ & $\mathrm{Q}$ & $\mathrm{T}$ & $\mathrm{K}$ & $\mathrm{K}$ & $\mathrm{K}$ & $\mathrm{Q}$ & W & $\mathrm{C}$ \\
\hline
\end{tabular}

TAT AAC TGT GAA GAA GAG GCC ATG TAC CAC TGC TGC TGG AAC ACG TCA TAT TGC

\begin{tabular}{|llllllllllllllllll|}
\hline $\mathrm{Y}$ & $\mathrm{N}$ & $\mathrm{C}$ & $\mathrm{E}$ & $\mathrm{E}$ & $\mathrm{E}$ & $\mathrm{A}$ & $\mathrm{II}$ & $\mathrm{Y}$ & $\mathrm{H}$ & $\mathrm{C}$ & $\mathrm{C}$ & $\mathrm{W}$ & $\mathrm{N}$ & $\mathrm{T}$ & $\mathrm{S}$ & $\mathrm{Y}$ & $\mathrm{C}$ \\
\hline
\end{tabular}

TCC ATC AAA TGC CAG CAG GAG CAC TGG CAC GCC GAT CAC AAA CGT ACC TGC CGC

\begin{tabular}{|llllllllllllllllll|}
\hline $\mathrm{S}$ & $\mathrm{I}$ & $\mathrm{K}$ & $\mathrm{C}$ & $\mathrm{Q}$ & $\mathrm{Q}$ & $\mathrm{E}$ & $\mathrm{H}$ & $\mathrm{W}$ & $\mathrm{H}$ & $\mathrm{A}$ & $\mathrm{D}$ & $\mathrm{H}$ & $\mathrm{K}$ & $\mathrm{R}$ & $\mathrm{T}$ & $\mathrm{C}$ & $\mathrm{R}$ \\
\hline
\end{tabular}

CGG AAG AGA TGA GCT ACA GCA GGA CAC GCC CTT TCC TCT TGA CTC CAC CCA CCA \begin{tabular}{|lllll}
\hline$R$ & $K$ & $R$ & $*$ \\
\hline
\end{tabular}

CGAGACACGCTAT TGGGTAGATTTT AAC ACT TCCCACCCT CCC CCC TGGCCACGG ATT CTT GATTT GTAGCC AGC ATCTTA AACCCAGCTCCAC AGAACACTTTTATCGGGG ACATTT TGC TGAGTT GCG ATG AAT GCT AAC AGGGC AAGCCAGTGCGGGAT TGCACAATCTTTGCGGAGGTT GATTTT AACGGT ATC CTT TTT CTT TTC ACATAT CCCTTTTT CGGTTT TACCTTTTT GTT T GCTGTACGACAGAAAACAGCC TTGCTCGCTTACAAG ACAGAC TAGCTGAAATGT GAAGTACT AGTTATCTTTTT AAACACA ACTTAATTTGAAGCT ATGTAG ATATTTGACTTT TTT ATATGAGCG AAT AAT GTCAGCCTCTT GCATTG AGATGGTGAAGT T GGTGCTT TTAAAC TCG ACG GTT GGTTTT GAATCA GTAGTT GTG ATG TCT TTT TTT CTT TTCTT TGG GGA ACA GGG TTT AAA GATGGCAAGTCATGTCTGTCT GAACGATACAAT CTT CCATTAATG AAT ATGCAC ATT TC ATG GAT ACACCT TTT AAT AGGC CTTTTCATTAGTA ACG AAAAACTAAATGATGTGC TAATTT TAGGGTCCATTTCTGTAG ATT GC ATACTAAAT CTT AAT GAA GCGTGGAGAAAT ATCACCAGTCCTTTT AAGGAAGAATGAACG AAACCT GACGAT TTT AT ATT GCAACATTGAAATCAGAC TAAGATT GTACAG AGATCAGTGTAA AGT AAACAATCAGAAATT ATCTCT ATAGGGGTT TATCACCG AGAGTT GTGGCACTT TTTGAACTT AAAAATGATTTAAAAATCTCCTCAAGCCGCTCCAAACCT GAT ATT AAG TGCTGCTCTAT GAAAAT TTCTGCA CTTAGACTCC ATC CGC TTT CATTTT ATG GAAATAGAG CAG CTTGAACGC ACT ACT AAG ATTCT CCT TTT GTGTTT TTC ATT AAAAGAG CAGGTT TGG AATGAC ACG ATG AGG AGT AAATGCTAAAAT TAG AATTTTGAGGTGGATTA ATATACCTT TAA ATA TTGCAAT AAG AAATTCTAAGTACAAATGATT AAG ATC TATCTTTAG AGT TTT GTCTAAGCTGA AGG ATGTAGGGG AAAATG TGAGGTT TTCGCACAGGACCAT ACT TGCGCGCGCACC TTT GTTCTGTTT CTC TCTTAAGTTCT GGATGCGTC TTAAATCAA GTCT GAT ACA TCC AGG TTT CTG TTT CTC TTT CGC TCC CTT CCC AAC CTC ACC GTT GCACTACATGT AAA TAACTG TTT GCC GCTAACATTG ACT GAT GAC GTT TGC ACG TTA GCA TCT GTACAT TTC ATG AAC GCATCG ACT GT GTATTT GAT AAA GTC AGT CTGTAAAGGAAAAAAA AAC ACC AAT ATT TGT GAT TTT AACGGT AATCTG TTCCAT TCC AGTGT GCATGAAATCAGGTTGTG TGTACCT AATTTT AAT CTTGCGTGTCATCGGTGATGC AGT ATGTCTTTTTGGTTTTCT AGGGT AATCTGACACCACTTTGT AATGCCAAGT AACCCT TTTTTT AAATCC AAATTT CATTTTT TACTT ATATTT ATGCGGACAGAATAATCACT ACT GAGAAT TTCCGAC ACCCAG AGAGAAGTGTGC TAT ACG AAC ATC TGTCTT ACATGT GCATACGAGTTAAAATG TGG TGT AAACGT TTC TTCCGAC ACC CAG AGAGAAGTG TGC TAT ACG AAC ATC TGTCTT ACA AGT GCATACGAGTTAAAATG TGG TGT AAACGT TTC
CCTTTTC TTGCAT TTC ATT ATG TAACAG TAC TAT GTATAAATAAAACAT ATC AACCGG TAAAAAAAAAAAAAAAA $3^{\circ}$

(b)

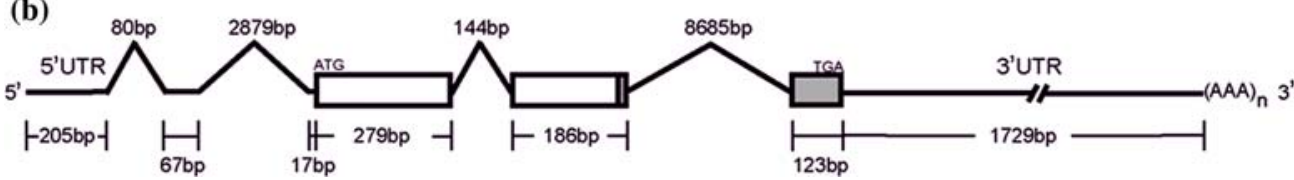

Figure 1. Nucleotide, deduced protein, and genomic organization of bram1. Panel (a) shows the nucleotide and deduced amino acid sequences of BRAM1. The open reading frame is presented in uppercase font. Start and stop codons are underlined. The MYND domain is specified within a solid box. Panel (b) shows gene structure of braml. Five exons are separated by four introns $80,2879,144$, and 8685 bp in length. 
(a) ZBRAM hBRAM1 MBRAM1 BRA-1 BRA-2

CG8569 CG1815

zBRAM1 hBRAM1 mBRAM1 BRA-1

BRA-2

CG8569

CG1815

zBRAM1

hBRAM1

MBRAM1

BRA-1

BRA-2

CG8569

CG1815

zBRAM1

hBRAM1

mBRAM1

BRA-1

BRA-2

CG8569

CG1815

zBRAM1

hBRAM1

mBRAM1

BRA-1

BRA-2

CG8569

CG1815

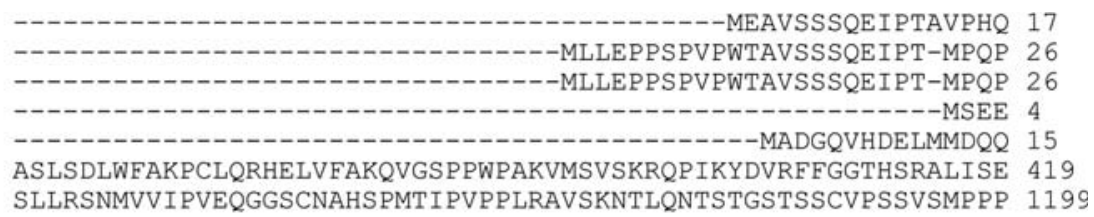

:

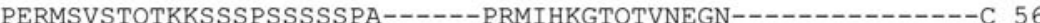

IEKVSVSTQTKKLSASS-----------PRMLHRSTQTTNDGV--------------C 59

IERVSVSTQTKKLSASS------------PRMLHRSTQTTSDGV--------------C 59

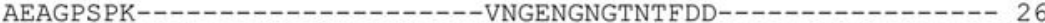

QQQGVVPQQGDIHLSPIDKDLGD------AALENNVRQYHLDG--------------- 52

RDITPIESDIQSHIKPRNSRALS------AAIKELQCHMMLSHYSASLFG------FHAD 467

LAGLS IPPVATPTSQEES ITNSGQPVGLLASALNGTANDVLSSDSIPNDPITPGLATALS 1259

QNMCHDKYSKIFSDVKEMMKAE----0.--NKRETERVLKEALDKLRGEM 98

QSMCHDKYTKIFNDFKDRMKSD--------------HKRETERVVREALEKLRSEM 101

QSMCHDKYTKIFNDFKDRMKSD-------------HKRETERVVREALEKLRSEM 101

-LYVDDKMRRMIVDLQRQWLTD----------------YHDSREKSLVALTEKLHQEF 67

-VVVSEGMKRMI IDLQRHWLSE----------------YHASREKCLVELTEKLHQEF 93

PTVAENLIKVALSHCTESTETS---------------ASGKRGRPPTPATPGAAKNR 509

EMLLHTGVPKLIARPRGALRSDGSQIYPSQAGPVSQKLKENAHKITDYFISVIEDTLSDM 1319

$\begin{array}{ccc}: & : & : \\ \text { EEEKRQAVNKAVS--- } & \text { :- }\end{array}$ EEEKROAVNKAVA-------NMOGEMDRKCKOVKEKCKEEFVEEIKKLATOHKOLISOT- 153 EEEKRQAVNKAVA-------SLQGDMDRKGKQLKEKCREEFVEEIKKLAAQHKQLISQT- 153 MEDQERVRRDLLV-------QFKIELDQTKEELEKKHAENLKEEIEKLSEKHQRELAVA- 119 MMDQQKIRSELLQ------QEKDELEQTRADLENKHRENLKMESAKLNEKHKRELVAS- 145 RLNNTTSNTSSPVPIR----GIPDSVAYDSLTAEILQAHNDLLNCRRELSATQRKLAEV- 564 ATGDQSVLQARIAGLSLENERLKQHYDRQINDLHRTSELMISEMRKTLEQEHKRVISELR 1379 $::$ :

--

-----------KKKQWCYNCEEEAMYHCCWNTSYCS I KCQQEHWHAEHKRTCRRKR- 198

--------KKKQWCYNCEEEAMYHCCWNTSYCS I KCQQEHWHAEHKRTCRRKR- 198

$--------K K K O W C W O C N S E A I Y H C C W N T A Y C S V E C Q Q G H W O I-H R K F C R R K K S 164$

---------RKKQWCWSCDNEAI YHCCWNTAYCSVECQQGHWQT-HRKFCRRKKG 190

-----KRKQWCYHCLDEAVFNCCFTASYCSVECQRRDKRR-HQASCKVTH- 608

QQNAIELMRAVEEAKRKQWCANCMREAQLYCCWNTSYCDYPCQQLHWPG-HSATCGQSVP 1438

(b)

Identity Similarity

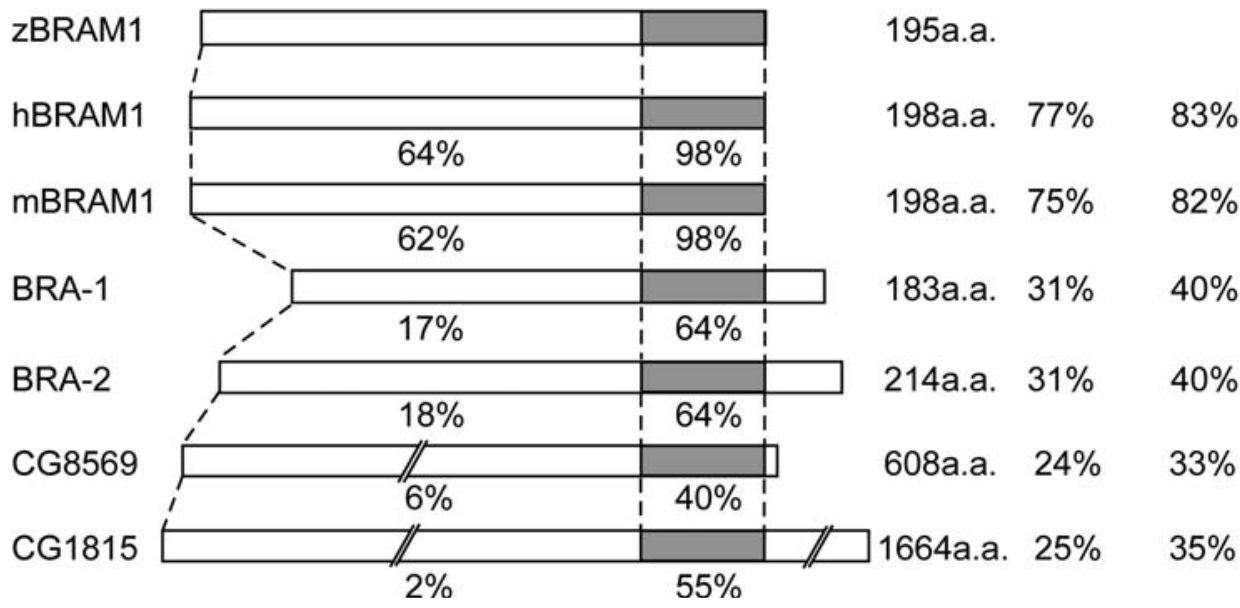

Figure 2. Comparison of zebrafish BRAM1 and its homologs. Panel (a) shows alignment of BRAM1 proteins from zebrafish (z), human (h), mouse (m), C. elegans (BRA-1 and BRA-2), and Drosophila (CG8569 and CG1815). The asterisk (*) indicates identical amino acids; (:) represents a strong similarity; (.) implies weaker similarity; and hyphens (-) indicate gaps in the alignment. The MYND domain is underlined. Panel (b) shows similarities and identities of zebrafish BRAM1 with its homologs. The MYND domain is highlighted within a gray box. The percentage identities and similarities between whole sequences and zebrafish BRAM1 are shown in bold. The percentage identity of the $\mathrm{N}$-terminal and C-terminal regions is indicated below the structure maps. The numbers of the predicted amino acid sequence are specified on the right. 
(a)

Oh $4 \mathrm{~h} \quad 8 \mathrm{~h} 10 \mathrm{~h} 12 \mathrm{~h} 16 \mathrm{~h} 24 \mathrm{~h} 72 \mathrm{~h} 144 \mathrm{~h}$ Adult

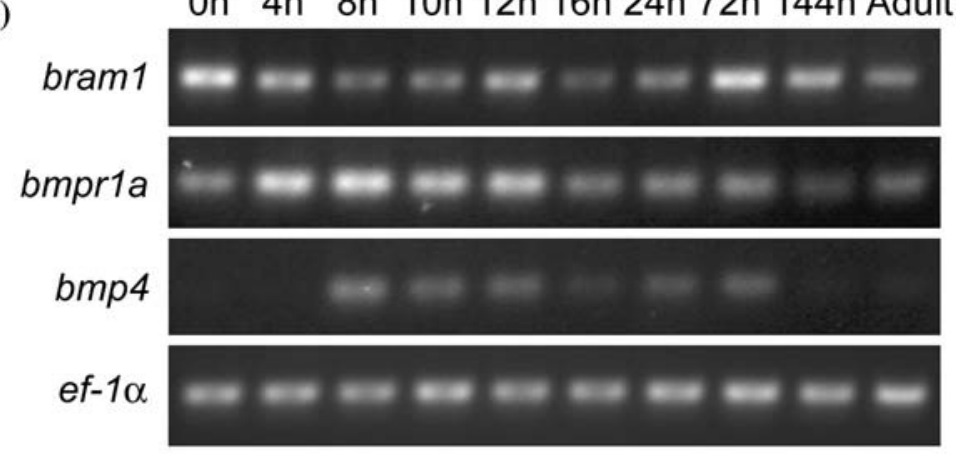

(b)
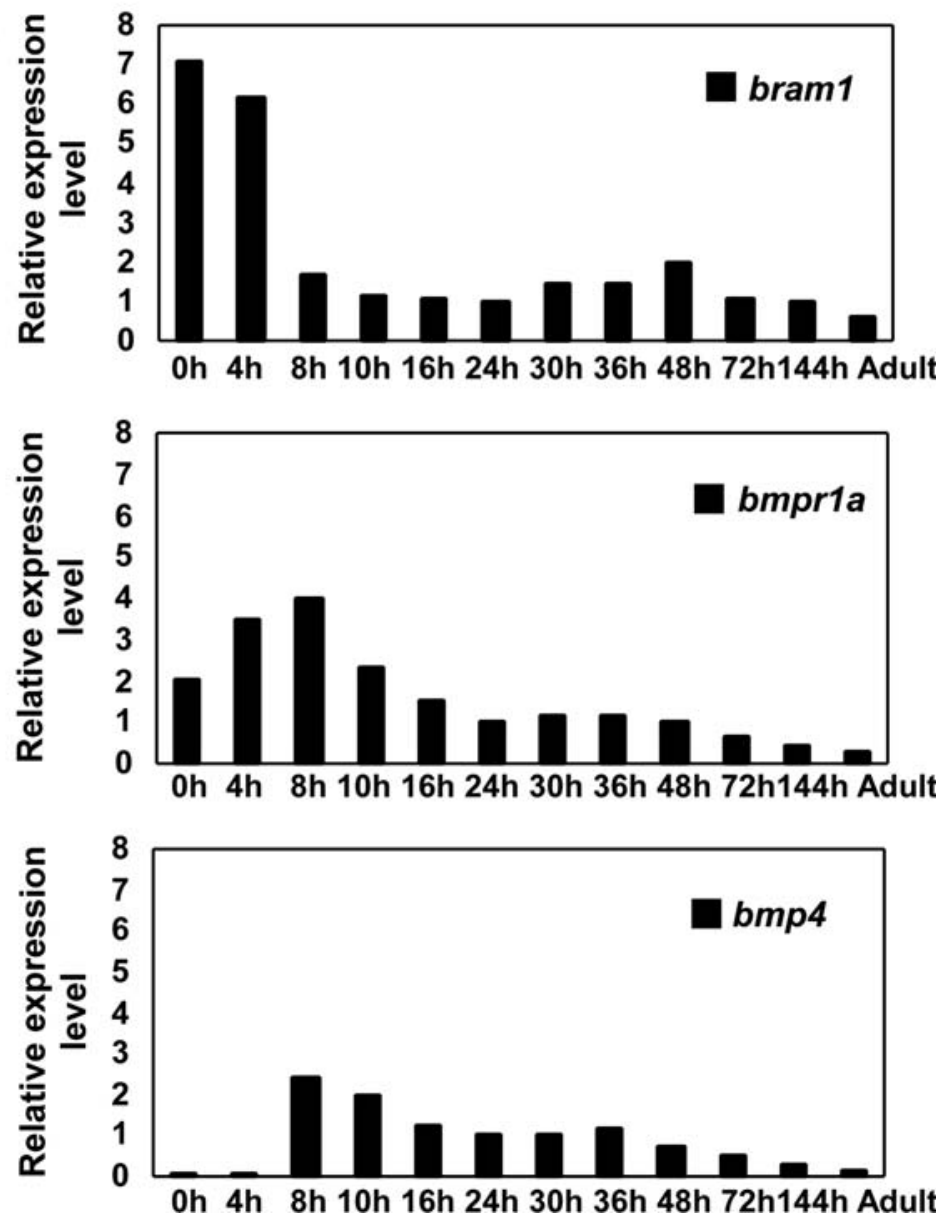

Figure 3. Gene expression analysis of bram1 during different zebrafish embryonic developmental stages. Panel (a) shows RT-PCR analysis of braml, bmprla, bmp4 at ten developmental stages. Amplified DNA products were separated by electrophoresis on 2\% agarose gels. Control PCR products were generated using primers specific for the $e f-1 \alpha$ gene. Panel (b) shows real-time RT-PCR analysis of braml transcripts at twelve different developmental stages. Total RNA from different stages was isolated, and gene expression determined by Faststart PCR, using reverse-transcribed cDNA. Relative expression of braml, bmprla, and bmp4 was normalized in comparison to that of internal control, ef- $1 \alpha$.

bmp4 are expressed simultaneously, supporting the potential cooperation of these three proteins in the BMP signaling pathway. Thus, high braml expres- sion during the early developmental stage may contribute to cell fate and influence organogenesis during later development. 
Spatiotemporal expression pattern of the zebrafish bram1 gene

We analysed the bram 1 expression pattern during early embryonic development by whole-mount in situ hybridization with zebrafish embryos from the 2-cell stage to $72 \mathrm{hpf}$, using a digoxigenin-labeled riboprobe. As shown in Figure 4, braml transcripts were uniformly expressed throughout the embryo in cleavage and blastula stages, and strong staining for braml was detected. These findings indicate that maternally supplied bram 1 transcripts are ubiquitously and uniformly distributed in all blastomeres (Figures $4 a, b$ ). During gastrulation, lower level of braml transcripts are present (Figure 4c), consistent with data obtained from real-time RT-PCR experiments. At the tailbud stage, braml was expressed throughout the embryos. During the somitogenesis stages, expression was restricted to the ventral region of the trunk and anlagen of the eyes (Figure 4d). At $24 \mathrm{hpf}$, faint uniform expression of braml was
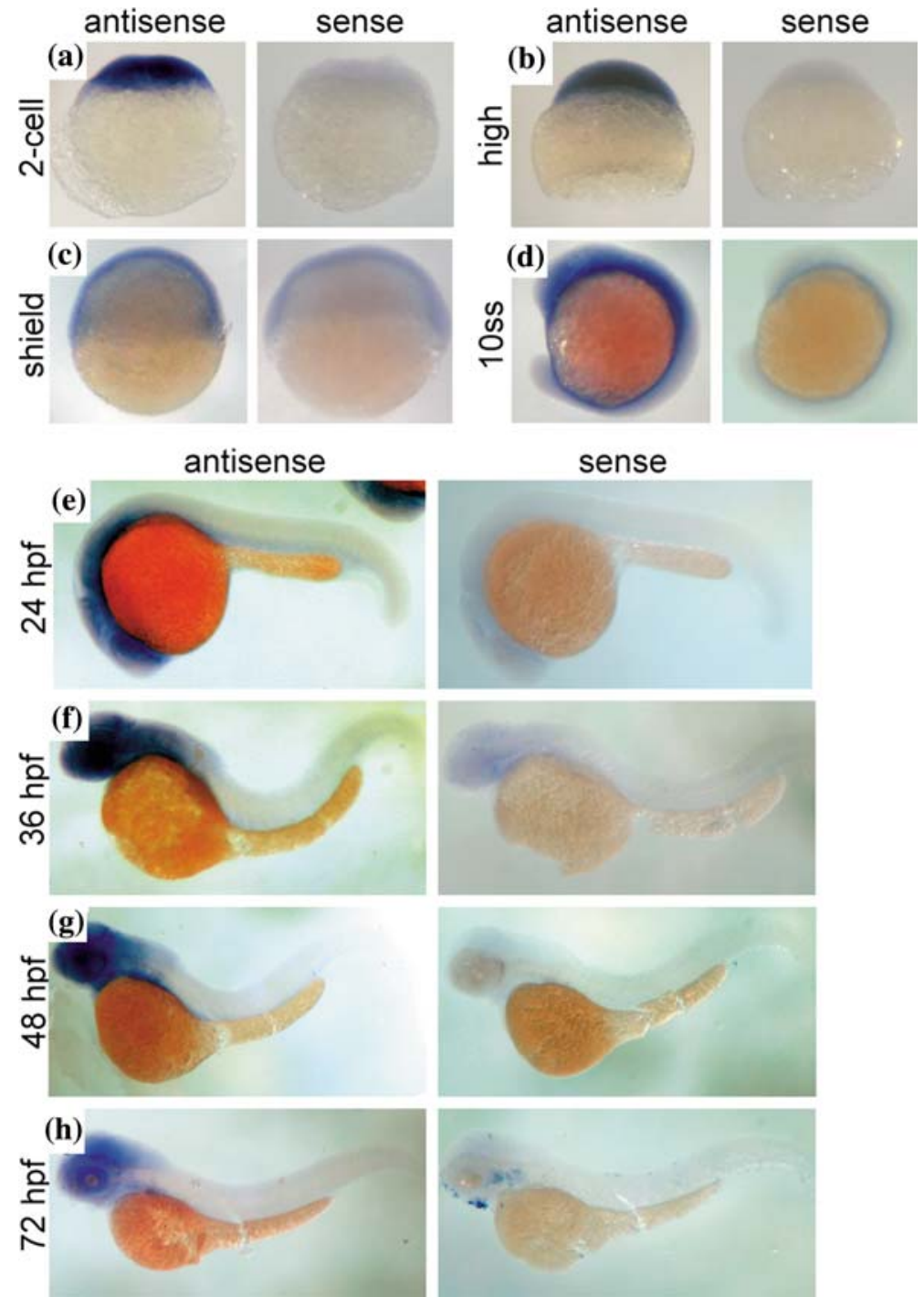

Figure 4. Expression pattern of bram1 during embryonic development. Embryos from two-cell (a), high (b), shield (c), 10-somites (d), $24 \mathrm{hpf}(\mathrm{e}), 36 \mathrm{hpf}(\mathrm{f}), 48 \mathrm{hpf}(\mathrm{g}), 72 \mathrm{hpf}(\mathrm{h})$ stages were analyzed using whole-mount in situ hybridization by probing with digoxigenin-labeled braml-specific antisense probes. 
(a) BMPRIA-HA

Flag-BRAM1 1-195)

Flag-BRAM1 (67-195)

Flag-BRAM1 (1-128)

Flag-BRAM1 (129-195)

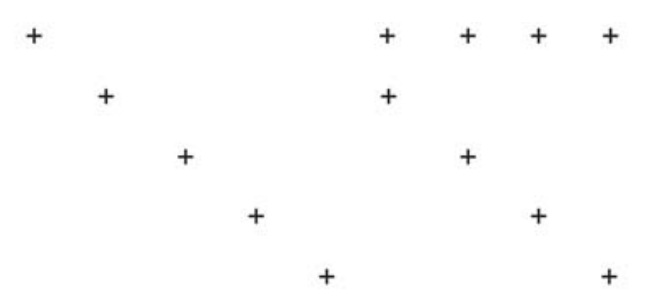

IP: $\alpha$ Flag blot: $\alpha \mathrm{HA}$

blot: $\alpha \mathrm{HA}$

blot: $\alpha$ Flag

(b)

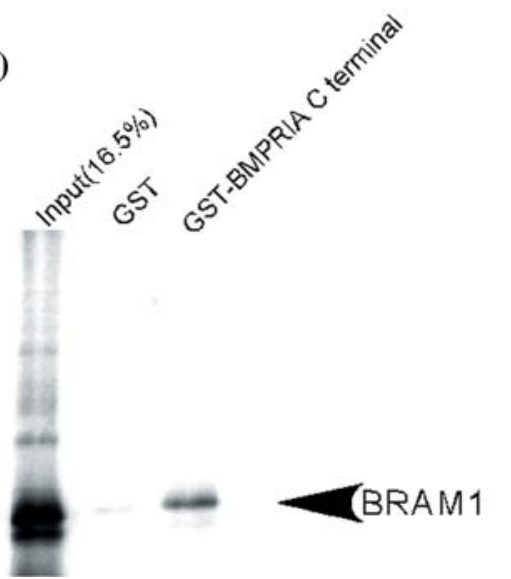

(c)
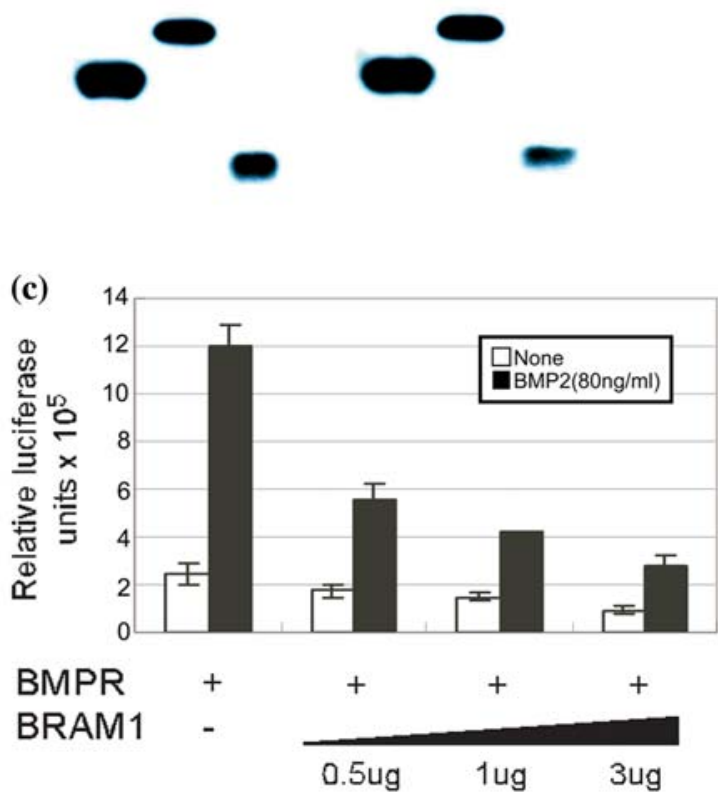

Figure 5. BRAM1 interacts with the BMP receptor to downregulate the BMP signaling pathway. Panel (a) shows the result of co-immunoprecipitation of zebrafish BRAM1 and BMPRIA. COS-7 cells were transiently transfected with zebrafish BMPRIAHA and Flag-zBRAM1(1-195), Flag-zBRAM1(67-195), Flag-zBRAM1(1-128) or Flag-zBRAM1(129-195) deletion constructs, followed by immunoprecipitation with anti-Flag, and western blot analysis with anti-HA antibodies. Panel (b) shows interactions between BRAM1 and BMPR-IA, as determined by GST-pull-down assays. [ ${ }^{35}$ S]Met-labeled BRAM1 was generated by in vitro transcription and translation. BRAM1 was incubated with affinity-purified GST-BMPR C terminal fusion protein, and recovered using glutathione-Sepharose beads. Panel (c) shows BRAM1 inhibits BMP signaling pathways. Data from experiments involving the co-transfection of zebrafish BMPRIA-HA and Flag-BRAM1-expressing constructs $(0.5,1, \& 3 \mu \mathrm{g})$ with a BMPresponsive reporter gene construct, $\mathrm{p}(\mathrm{SBE})_{4}$-luc show that zebrafish BRAM1 interferes with BMP signaling in $3 \mathrm{~T} 3$ cells.

observed in the brain and eyes (Figure 4e). At $36 \mathrm{hpf}$, braml transcripts increased in the retina, cerebellum, and buds (Figure 4f). At 48 and $72 \mathrm{hpf}$, decreased braml expression was evident throughout the brain (Figure 4g, h). It worths noting that the expression pattern of bmp receptor is overlapping with the expression pattern of zebrafish braml [25-30].
Zebrafish BRAM1 specifically interacts with zebrafish BMPR-IA and downregulates BMP signaling in mammalian cells

Analogous to human and mouse BRAM1, zebrafish BRAM1 interacts with its BMP type I receptor. Thus, we investigated whether this association affects the BMP signaling pathway. COS-7 
cells were transiently transfected with FlagzBRAM1 and zBMPRIA-HA, followed by immunoprecipitation with anti-Flag antibody. Flag-tagged BRAM1 proteins were precipitated with anti-Flag antibody, and immunoblot analysis revealed co-precipitation of BMPRIA-HA (Figure 5a). Reprobing with the anti-Flag antibody confirmed that an equivalent level of BRAM1 protein was precipitated. Our data show that BRAM1 interacts specifically with the cytoplasmic domain of BMPR-IA in mammalian cells. To analyze the BMP receptor binding domain of BRAM1, deletion mutants, FlagBRAM1(67-195), Flag-BRAM1(1-128), and Flag-BRAM1(129-195) (Figure 5a) were transiently expressed, along with BMPR-IA-HA.

Flag-tagged BRAM1 proteins were precipitated with anti-Flag antibody, and immunoblot analysis revealed co-precipitation of BMPRIAHA. Immunoprecipitation data showed that only Flag-BRAM1(1-128) did not co-precipitate with BMPRIA-HA. In contrast, the other deletion mutants precipitated with BMPR-IA. Our data thus strongly imply that the C-terminal region of BRAM1 interacts with BMPR-IA, particularly through the MYND domain of BRAM1.

Zebrafish BRAM1 interacts with BMPR-IA through the MYND domain in mammalian cells. We additionally performed a GST pull-down assay to determine whether the binding of zebrafish BRAM1 to BMPR-IA is direct. Specifically, the GST-BMPRC' fusion protein was expressed in BL21 bacterial cells and affinity column-purified (Figure 5b). Zebrafish BRAM1 was labeled with $\left[{ }^{35} \mathrm{~S}\right]$ using in vitro transcription and translation, and incubated with GST-BMPRC ${ }^{\prime}$ using glutathione-Sepharose beads overnight at $4{ }^{\circ} \mathrm{C}$ to pull down the protein complexes. In vitro-translated BRAM1 interacted with GST-BMPRC' (Figure $5 \mathrm{~b}$ ), indicating that the homolog is directly associated with BMPR-IA in zebrafish.

To establish the function of the BRAM1BMPRIA complex in BMP signaling, cells were co-transfected overnight with the specified BRAM1-expressing vector, BMPR-IA expressing vector, and BMP-responsive promoter-reporter plasmids ((SBE) 4 -Luc), followed by serum starvation $12 \mathrm{~h}$, and treated with BMP2 or left untreated for $16 \mathrm{~h}$. BRAM1 inhibited the transcriptional activity induced by BMP2 in a dose-dependent manner (Figure 5c). The data suggest that the
BRAM1 inhibits BMP signaling, possibly through its C-terminal MYND domain.

Thus, in this study, we have reported the isolation of the zebrafish braml gene, and have additionally examined the developmental profile of this gene in zebrafish, which is coordinated with the expression of BMP and BMP type I receptor. The direct interactions between zebrafish BRAM1 and BMP receptor type IA, and inhibition of BMP-mediated reporter gene expression, support a potential role of zebrafish BRAM1 in BMPmediated signaling. Further analyses of the interactions between BRAM1 and mediator molecules in BMP signaling pathways are required to elucidate the mechanism by which BRAM1 inhibits BMP signaling. It would additionally be feasible to investigate the physiological role of BRAM1 in zebrafish development by morpholino knockdown of BRAM1 expression, followed by in vivo analysis of fish development.

\section{Acknowledgements}

The authors thank Professor Peter ten Dijke of the Ludwig Institute for Cancer Research for the (SBE) 4 -luc plasmid. This work was supported by grants from National Health Research Institute, Taiwan (NHRI-EX94-9214BI), and Chang-Gung Memorial Hospital and Chang-Gung University (CMRPD32006), Taiwan.

\section{References}

1. Nohe A., Keating E., Knaus P. and Petersen N.O., Signal transduction of bone morphogenetic protein receptors. Cell Signal 16: 291-299, 2004

2. ten Dijke P., Korchynskyi O., Valdimarsdottir G. and Goumans M.J., Controlling cell fate by bone morphogenetic protein receptors. Mol. Cell. Endocrinol. 211: 105113, 2003.

3. Wrana J.L., Attisano L., Wieser R., Ventura F. and Massague J., Mechanism of activation of the TGF- $\beta$ receptor. Nature 370: 341-347, 1994.

4. Heldin C.H., Miyazono K. and ten Dijke P., TGF- $\beta$ signaling from cell membrane to nucleus through SMAD proteins. Nature 390: 465-471, 1997.

5. Kretzschmar M., Liu F., Hata A., Doody J. and Massague J., The TGF- $\beta$ family mediator Smad 1 is phosphorylated directly and activated functionally by the BMP receptor kinase. Genes Dev. 11: 984-995, 1997.

6. Macias-Silva M., Abdollah S., Hoodless P.A., Pirone R., Attisano L. and Wrana J.L., MADR2 is a substrate of the TGF- $\beta$ receptor and its phosphorylation is required for 
nuclear accumulation and signaling. Cell 87: 1215-1224, 1996.

7. Kawabata M., Inoue H., Hanyu A., Imamura T. and Miyazono K., Smad proteins exist as monomers in vivo and undergo homo- and hetero-oligomerization upon activation by serine/threonine kinase receptors. EMBO J. 17: 4056-4065, 1998.

8. Lagna G., Hata A., Hemmati-Brivanlou A. and Massague J., Partnership between DPC4 and SMAD proteins in TGF- $\beta$ signaling pathways. Nature 383: 832-836, 1996.

9. Wu R.Y., Zhang Y., Feng X.H. and Derynck R., Heteromeric and homomeric interactions correlate with signaling activity and functional cooperativity of Smad3 and Smad4 DPC4. Mol. Cell. Biol. 17: 2521-2558, 1997.

10. Derynck R. and Zhang Y.E., Smad-dependent and Smadindependent pathways in TGF- $\beta$ family signaling. Nature 425: 577-584, 2003.

11. ten Dijke P. and Hill C.S., New insights into TGF- $\beta$-Smad signaling. Trends Biochem. Sci. 29: 265-273, 2004.

12. Yamaguchi K., Shirakabe K., Shibuya H., Irie K., Oishi I., Ueno N., Taniguchi T., Nishida E. and Matsumoto K., Identification of a member of the MAPKKK family as a potential mediator of TGF-beta signal transduction. Science 270: 2008-2011, 1995.

13. Shibuya H., Yamaguchi K., Shirakabe K., Tonegawa A., Gotoh Y., Ueno N., Irie K., Nishida E. and Matsumoto K., TAB1: an activator of the TAK1 MAPKKK in TGFbeta signal transduction. Science 272: 1179-1182, 1996.

14. Nakao A., Afrakhte M., Moren A., Nakayama T., Christian J.L., Henchel R., Itoh S., Kawabata M., Heldin N.E., Heldin C.H. and ten Dijke P., Identification of Smad7, a TGF- $\beta$-inducible antagonist of TGF- $\beta$ signaling. Nature 389: 631-635, 1997.

15. Hata A., Lagna G., Massague J. and Hemmati-Brivanlou A., Smad6 inhibits BMP/Smad1 signaling by specifically competing with the Smad4 tumor suppressor. Genes Dev. 12: 186-197, 1998.

16. Zwijsen A., Verschueren K. and Huylebroeck D., New intracellular components of bone morphogenetic protein/ Smad signaling cascades. FEBS Lett. 546: 133-139, 2003.

17. Murakami G., Watabe T., Takaoka K., Miyazono K. and Imamura T., Cooperative inhibition of bone morphogenetic protein signaling by Smurfl and inhibitory Smads. Mol. Biol. Cell 14: 2809-2817, 2003.

18. Kurozumi K., Nishita M., Yamaguchi K., Fujita T., Ueno N. and Shibuya H., BRAM1, a BMP receptor-associated molecule involved in BMP signaling. Genes Cells 3: 257264, 1998.
19. Chung P.J., Chang Y.S., Liang C.L. and Meng C.L., Negative regulation of Epstein-Barr virus latent membrane protein 1-mediated functions by the bone morphogenetic protein receptor IA-binding protein, BRAM1. J. Biol. Chem. 277: 39850-39857, 2002.

20. Georgi L.L., Albert P.S. and Riddle D.L., daf-1, a $C$. elegans gene controlling dauer larva development, encodes a novel receptor protein kinase. Cell 61: 635-645, 1990.

21. Morita K., Shimizu M., Shibuya H. and Ueno N., A DAF1-binding protein BRA-1 is a negative regulator of DAF-7 TGF-beta signaling. Proc. Natl. Acad. Sci. USA 98: 6284 $6288,2001$.

22. Estevez M., Attisano L., Wrana J.L., Albert P.S., Massague J. and Riddle D.L., The daf-4 gene encodes a bone morphogenetic protein receptor controlling $C$. elegans dauer larva development. Nature 365: 644-649, 1993.

23. Inoue T. and Thomas J.H., Targets of TGF-beta signaling in Caenorhabditis elegans dauer formation. Dev. Biol. 217: 192-204, 2000.

24. Tsang M., Kim R., de Caestecker M.P., Kudoh T., Roberts A.B. and Dawid I.B., Zebrafish nma is involved in TGFbeta family signaling. Genesis 28: 47-57, 2000.

25. Chen J.N., van Eeden F.J., Warren K.S., Chin A., Nusslein-Volhard C., Haffter P. and Fishman M.C., Leftright pattern of cardiac BMP4 may drive asymmetry of the heart in zebrafish. Development 124: 4373-4382, 1997.

26. Yelick P.C., Abduljabbar T.S. and Stashenko P., zALK-8, a novel type I serine/threonine kinase receptor, is expressed throughout early zebrafish development. Dev. Dyn. 211: 352-361, 1998.

27. Yan Y.T., Gritsman K., Ding J., Burdine R.D., Corrales J.D., Price S.M., Talbot W.S., Schier A.F. and Shen M.M., Conserved requirement for EGF-CFC genes in vertebrate left-right axis formation. Genes Dev. 13: 2527-2537, 1999.

28. Bisgrove B.W., Essner J.J. and Yost H.J., Multiple pathways in the midline regulate concordant brain, heart and gut left-right asymmetry. Development 127: 3567-3579, 2000.

29. Chen J.N. and Fishman M.C., Genetics of heart development. Trends Genet. 16: 383-388, 2000.

30. de Caestecker M.P., Bottomley M., Bhattacharyya S., Payne T.L., Roberts A.B. and Yelick P.C., The novel type I serine-threonine kinase receptor Alk8 binds TGF-beta in the presence of TGF-betaRII. Biochem. Biophys. Res. Commun. 293: 1556-1565, 2002. 